\title{
Volatile aroma compounds and sensory characteristics of traditional banana wine "Urwagwa" of Rwanda
}

\author{
François Lyumugabe*, Innocent Iyamarere, Michel Kayitare, Joseph Rutabayiro \\ Museveni and Emmanuel Bajyana Songa \\ Biotechnology unit, College of Science and Technology, University of Rwanda, Avenue de l'Armée, Po.Box. \\ 3900 Kigali, RWANDA. \\ *Corresponding author: flyumugabe@gmail.com; 1yumugishawimana@yahoo.fr
}

\begin{abstract}
Urwagwa, produced mainly from the fermentation of banana juice, is the oldest and popular Rwandan traditional alcoholic beverage. In the present paper, the aroma profiles of Urwagwa wine samples collected from the districts of Rulindo and Ngoma were investigated. Headspace/ Solid-Phase Micro Extraction (HS- SPME) and gas chromatography - mass spectrometry (GC/MS) were applied for the analysis of volatile aroma compounds. Odour Active Values (OAVs) and sensory analysis were also performed to define the aromatic profile of Urwagwa wine. The findings showed that the aroma profiles of two types of Urwagwa wines analyzed were not significantly different. Forty eight volatile aroma compounds, including esters, higher alcohols, acids, terpenes, furan and phenol were identified and quantified in Urwagwa wines. Among them, ethyl caprylate, ethyl caproate, ethyl caprate, ethyl acetate, isoamyl acetate, ethyl acetate, ethyl butyrate, phenethyl acetate, phenethy alcohol, caprylic acid, 1-octanol and isovaleric acid exhibited OAVs $>1$, and are considered as the major contributors of aromatic character of Urwagwa wine; described as fruity, floral, banana, sweet and fatty notes. However, the overall aroma profiles of the investigated Urwagwa wines were dominated by the fruity note due to the high amount of ethyl caprylate, ethyl caprate and ethyl caproate in this Rwandan traditional banana wine.
\end{abstract}

Keywords: Aroma compounds; Sensory analysis; Banana wine, Urwagwa 


\section{Résumé}

Urwagwa, produite principalement à partir de la fermentation du jus de banane, est la boisson alcoolique traditionnelle rwandaise la plus ancienne et la plus populaire. Dans le présent article, les profils d'arômes d'échantillons de vin Urwagwa collectés dans les districts de Rulindo et de Ngoma ont été étudiés en utilisant la technique de Micro-extraction tête / espace solide (HS-SPME) et chromatographie en phase gazeuse - spectrométrie de masse (GC / MS) et valeurs actives d'odeur. Les résultats ont montré que les profils aromatiques de deux types de vins Urwagwa analysés n'étaient pas significativement différents. Quarantehuit composés aromatiques volatils, y compris les esters, les alcools supérieurs, les acides, les terpènes, le furane et le phénol ont été identifiés et quantifiés dans les vins Urwagwa. Parmi eux, le caprylate d'éthyle, le caproate d'éthyle, le caprate d'éthyle, l'acétate d'éthyle, l'acétate d'isoamyle, l'acétate d'éthyle, le butyrate d'éthyle, l'acétate de phénéthyle, le phénéthylène, l'acide caprylique, le 1-octanol et l'acide isovalérique sont les contributeurs du profile aromatique du vin Urwagwa; décrit comme fruité, floral, banane, notes sucrées et grasses. Cependant, le profil aromatique global de tous les vins Urwagwa étudiés était dominé par la note fruitée due à la grande quantité de caprylate d'éthyle, de caprate d'éthyle et de caproate d'éthyle dans ce vin de banane traditionnel rwandais.

Mots-clés: Composés aromatiques; Analyse sensorielle; Vin de banane, Urwagwa 


\section{INTRODUCTION}

Aroma, one of the most important factors determining the character and quality of wine, is due to the combined effects of a great number of volatile compounds belonging to heterogenous chemical groups, including alcohols, aldehydes, esters, acids, terpenes and other minor components which already are present in the fruits or being formed during the fermentation and maturation process (Verzera et al., 2008). According to legal definition, wine is the product obtained exclusively by alcoholic fermentation, total or partial, of fresh grapes, whether crushed or not, or grape must. However, in the new world, wine may refer to the fermented by-products of any fresh fruit or flower. Rwandan traditional wine, called generally Urwagwa (Kinyarwanda language), is produced mainly by alcoholic fermentation of juice extracted from special varieties of bananas, such as 'Indege', 'Inkati', 'intutu', 'kayuku', 'Gisukali' and 'Intokatoke (Nsabimana and van Staden, 2007). Wine maker generally blend banana varieties in the recipe but some process single banana variety to make wine.

Volatile aroma compounds are perceived by the odour receptor sites of the smell organ, i. e. the olfactory tissue of the nasal cavity. They reach the receptors when drawn in through the nose (orthonasal detection) and via the throat after being released by chewing (retronasal detection). The concept of aroma substances, like the concept of taste substances, should be used loosely, since a compound might contribute to the typical odour or taste of one food, while in another food it might cause a faulty odour or taste, or both, resulting in an offflavour. Hence, volatile aroma compounds are closely related to the product sensory profile which strongly impacts by the consumer's acceptability (Vilanova, 2006; Varela and Gàmbara, 2006). Sensory analysis has defined its role in the oenological industry identifying the causes of variation of perceived quality, the corrective actions thereby becoming instrument of quality control of wines (Lawless 1995; Muñoz, 2002). 
Urwagwa is a popular alcoholic beverage in Rwanda and play an important role in fulfilling social obligations (e.g. marriage, birth, baptism, etc.) and constitutes a significant source of income for the manufacturers and for national economy of Rwanda (Mukantwali et al., 2008). The manufacturing process of this traditional alcoholic beverage varies according to the know-how of each region of Rwanda and raw materials, thus leading to the production of different Urwagwa types in terms of alcohol content, colour, taste and shelf life (Munyangendo, 1983). Traditional process for the production of Urwagwa involves generally five mainly steps: ripening of green banana in warm pit covered with banana leaves and/or eucalyptus leaves (called Urwina in Rwandan language), peeling, banana juice extraction (mixing of ripe banana with spear glass, squeezing the mixture with their feet or hands), filtration of juice through grass held in calabash funnel and spontaneous fermentation. The fermentation process requires the addition of coarsely-ground, roasted sorghum malt and/or granulated sugars into the diluted banana juice, in a canoe-shaped wooden container known as "Umuvure" or in a clay pot (Shale et al., 2012, 2014), to improve the fermentation process, colour and flavour of final products.

Most studies conducted on Rwandan traditional banana wine have been focused to the production process, improvement of banana juice extraction methods, isolation and characterization of yeast strains involved in the fermentation (Munyangendo, 1983, Mukantwali et al., 2008, Shale et al., 2012), but the aroma profile of banana wine has not been yet fully investigated. The present work aimed to define the aroma profile of traditional banana wine "Urwagwa" from Rwanda. Headspace/ Solid-Phase Micro Extraction (HSSPME) and gas chromatography - GC-mass spectrometry (GC/MS) analysis were applied to determine the volatile aroma compounds. Odour Active Values (OAVs) were assessed, already successfully used for determining the contribution of each volatile compound as wine 
aroma. Sensory analyses were performed to define the overall flavor profile of Urwagwa wine.

\section{MATERIALS AND METHODS}

\subsection{Samples collection}

Twenty samples of traditional banana wine "Urwagwa" packaged in the polyethylene bottles (33 cL) were collected from Rulindo and Ngoma districts of Rwanda. The banana wines collected in the Rulindo district were made from Gisukari banana variety while those from Ngoma district were made from Kamaramasenge banana variety. The samples were stored in refrigerator at $5{ }^{\circ} \mathrm{C}$ and then analyzed after 5 days of the production. The production process of theses samples is described in Figure 1.

\subsection{Reagents}

The pure reference compounds (Phenethyl alcohol, 1-hexanol, 1-propanol, isobutyl alcohol, isoamyl alcohol, ethyl acetate, ethyl butyrate, ethyl caproate, ethyl caprate, ethyl caprylate, caproic acid, caprylic acid and acetic acid) used in this study were purchased from SigmaAldrich (Belgium). 3-octanol and absolute ethanol were purchased from Acros Organics (Geel - Belgium) and Sigma-Aldrich (Belgium), respectively.

Green banana (Gisukari or Kamaramasenge variety)

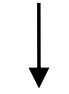

Ripening in warm pit covered with banana leaves 
Mixing with spear glass and mashed with

feet/or hand

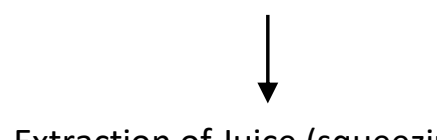

Extraction of Juice (squeezing) and filtration

through grass held in calabash funnel

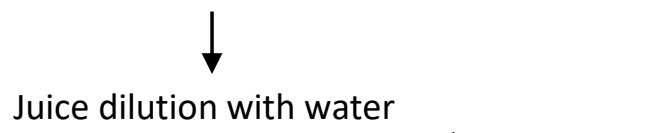

(1:3 ratios)

Roasted sorghum and

granulated sugar

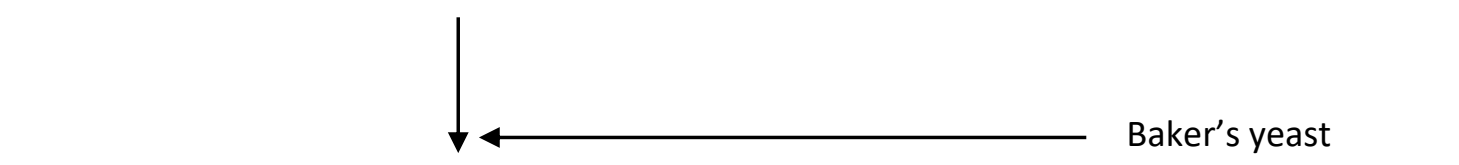

Fermentation of wort (in warm pit covered with banana

leaves) for 3 days

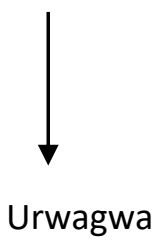

Figure 1. Flow diagram of production process of Rwandan traditional banana wine "Urwagwa" collected from Ngoma and Rulindo districts.

\subsection{Standard chemical analysis}

The samples were centrifiguted at $6000 \mathrm{x} \mathrm{g}$ for $10 \mathrm{~min}$, filtered through filter paper and analyzed by standard methods. The $\mathrm{pH}$ was measured using a $\mathrm{pH}$ meter 781 (Metrohm Herisau). Titratables acidity, expressed as a percentage lactic acid, was determined by 
titrating the samples with $0.1 \mathrm{~N} \mathrm{NaOH}$ to the phenolphthalein end point. Sugar content was measured as degree brix using a hand refractometer (ATAGO brand, Japan). Ethanol was determined by enzymatic method using the Megazyme assay Kit purchased from SigmaAldrich (Belgium). The free and total sulphites $\left(\mathrm{SO}_{2}\right)$ were measured by titration method using Vinmetrica $\mathrm{SO}_{2}$ analyser kit from Brouwland (Belgium).

\subsection{Volatile aroma compounds analysis}

\section{HS-SPME procedure}

Banana wine samples $(10 \mathrm{~mL})$ were pipetted into $20-\mathrm{mL}$ round-bottomed, amber glass headspace vials, each containing $2.5 \mathrm{~g}$ of $\mathrm{NaCl}$ and $5 \mu \mathrm{L}$ of the internal standard 3-octanol (100 mg/L in absolute ethanol), and then equilibrated at $30{ }^{\circ} \mathrm{C}$ for $10 \mathrm{~min}$ under agitation (Gerstel Agitator/Stirrer) at $500 \mathrm{rpm}$. After this period, the 50/30 $\mu \mathrm{m}$ Divinylbenzene / Carboxen / Polydimethylsiloxane (DVB/CAR/PDMS) fiber (Supelco Inc., Bellefonte, PA) was exposed in the headspace of the vial for $30 \mathrm{~min}$ with agitation at $250 \mathrm{rpm}$ and the extracted analytes from fiber were automatically desorbed in injection port of the GC-MS system at $250{ }^{\circ} \mathrm{C}$.

\section{Gas chromatography - mass spectrometry}

Analyses were carried out using an Agilent 7890 GC system equipped with a 5975C inert XL EI/CI mass selective detector (Agilent Technologies, Santa Clara, CA, USA), Thermal Desorption Unit (TDU, Gerstel), PTV inlet (CIS 4, Gerstel) and MPS 2 with headspace and DHS option (Gerstel). An HP-5 MS column (30 m x $0.25 \mathrm{~mm}$ ID) with a film thickness of $0.25 \mu \mathrm{m}$ was applied to extract volatile compounds from the headspace of above-prepared glass vial. The GC was equipped with a split-splitless injector which was held at $250^{\circ} \mathrm{C}$. After starting at $30{ }^{\circ} \mathrm{C}$, the oven temperature was raised in 3 steps after 2 min: $30-70{ }^{\circ} \mathrm{C}$ at10 
${ }^{\circ} \mathrm{C} / \mathrm{min}$ followed by $1 \mathrm{~min}$ at $70^{\circ} \mathrm{C}, 70-220^{\circ} \mathrm{C}$ at $4^{\circ} \mathrm{C} / \mathrm{min}$ and $220-280{ }^{\circ} \mathrm{C}$ at $20^{\circ} \mathrm{C} / \mathrm{min}$, and was finally held at $280^{\circ} \mathrm{C}$ for $6 \mathrm{~min}$. During these programs, a constant flow rate $(1.0$ $\mathrm{mL} / \mathrm{min}$ ) of the carrier gas (Helium) was maintained. Mass spectra were obtained by electronic impact (EI) scan mode (low mass: 30.0; high mass: 500.0; threshold: 150) and temperature source $\left(230^{\circ} \mathrm{C}\right)$ was generated.

\title{
Identification and quantification
}

The identification of volatile aroma compounds was achieved by comparing mass spectra obtained from the sample with those from the NIST and Pal1600k.L libraries Database or from the pure standards injected in the same conditions and by comparing the kovats index estimated for each compound on both chromatographic column with the values given in the literature (Pino et al., 2010; Lyumugabe et al., 2013; www. pherobase.com/database/kovats).

Selective ion monitoring was used for integrations of all chromatogram peaks and the quantification was conducted according to the internal standard (3-octanol) quantification method. Quantitative data of identified compounds were obtained by using the following formula: Analyte's concentration $=($ Peak area of analyte $/$ Peak area of internal standard $)$

\author{
$\mathrm{x}$ Emendation factor to internal standard \\ x Concentration of internal standard
}

The concentration of volatile aroma compounds for which there was no pure reference available was obtained by using the same emendation factor as one of the compounds with the most similar chemical structure (Perestrelo et al., 2006; Li et al, 2006, 2008).

\subsection{Odour activity values (OAVs)}


Odour activity values (OAVs) were performed to evaluate the contribution of each volatile aroma compounds in banana wine. OAVs were calculated using the equation $\mathbf{O A V}=\mathbf{c} / \mathbf{t}$, where $\mathbf{c}$ is the total concentration $(\mu \mathrm{g} / \mathrm{L})$ of each compound in the wine samples, and $\mathbf{t}$ is the odor threshold value $(\mu \mathrm{g} / \mathrm{L})$ of the compound in water/ethanol solution (Hellín et al., 2010); threshold values were obtained from information available in the literature (references are shown in Table 3).

\subsection{Descriptive sensory analysis}

Descriptive sensory analysis of banana wine was performed by a selected panel of ten assessors trained over five sessions according to the international standards (ISO 13299, 2003). A preliminary sensory assessment of Urwagwa aroma was conducted on 4 wine samples from Rulindo and Ngoma districts in order to obtain a list of descriptive attributes of aroma. The attributes that were recognised by at least $50 \%$ of the panel members were selected and put on the list. In the second phase, 16 samples of Urwagwa were presented in a randomized and balanced order, and the intensity of each attribute related to odour such as fruity, flora, banana, spicy, sweet, fatty and green/vegetable was quantified using a 9 points hedonic scale ranging from 1 (low intensity) to 9 (high intensity) according to the international standards (ISO 4121, 2003). Each evaluation was conducted in individual tasting booths at room temperature $\left(20^{\circ} \mathrm{C}\right.$ ) (ISO 8589, 1988) and $50 \mathrm{ml}$ of each wine was served in glasses labelled with a code and covered to prevent volatile loss (ISO 3591, 1977).

\subsection{Statistical Analysis}

The experiments were conducted in triplicate and the results were expressed as mean with standard deviation. Statistical analysis of the data was performed using SPSS Package Program. Statistical significance was taken at $95 \%$ confidence interval when $p<0.05$. When 
Analysis of Variance (ANOVA) revealed a significant effect $(\mathrm{p}<0.05)$, the data means were compared by the least significant difference (Duncan's Multiple Range test) test.

\section{RESULTS AND DISCUSSION}

\subsection{General composition of traditional banana wine "Urwagwa"}

Table 1 shows some physicochemical characteristics (ethanol content, $\mathrm{pH}$, titratable acidity, total sugars expressed in brix degree, total and free $\mathrm{SO}_{2}$ ) of traditional banana "Urwagwa" wine made from Gisukari (collected from Rulindo district) and Kamaramasenge (collected from Ngoma district) banana varieties.

Ethanol, principal metabolite produced by yeast (Sacharomyces cerevisiae) during the fermentation of banana juice, is essential to enhance the sensory attributes of other wine components, its concentration can significantly influence the aroma and taste of the produced wine. In this study, ethanol content of Urwagwa wine samples from Rulindo and Ngoma vineyards was observed to be $11.03 \pm 2.25(\mathrm{v} / \mathrm{v})$ and $7.53 \pm 1.16(\mathrm{v} / \mathrm{v})$, respectively. Low ethanol content observed in Urwagwa from Ngoma district can probably due to Kamaramasenge banana variety, whose concentration of fermentable sugars is low compared to Gisukari banana variety (Munyangendo, 1983).

Titratable acidity of Urwagwa samples from Gisukari and Kamaramasenge varieties ranged respectively around $5.76 \pm 0.21 \mathrm{~g} / \mathrm{L}$ and $5.41 \pm 0.33 \mathrm{~g} / \mathrm{L}$, and $\mathrm{pH}$ was between $3.87 \pm 0.13$ and $4.09 \pm 0.19$. The principal organic acids found in must or wine are tartaric, malic; to a small extent, citric and other acids. Tartaric and malic acid account for over $90 \%$ of titrable acidity. The composition and concentration of these organic acids within the wine is influenced by many factors such as variety, climatic region, and cultural practices; their presence contributes to both a wine's flavour and to its stability (Richard et al., 1988). 
Table 1. Some physicochemical characteristics of Urwagwa from Rulindo (made from Gisukari banana variety) and Ngoma districts (made from Kamaramasenge banana variety)

\begin{tabular}{lcr}
\hline & Rulindo & Ngoma \\
\hline $\mathrm{pH}$ & $3.87( \pm 0.13)$ & $4.09( \pm 0.19)$ \\
Titratable acidity $(\mathrm{g} / \mathrm{L})$ & $5.76( \pm 0.21)$ & $5.41( \pm 0.33)$ \\
Total sugar (Brix) & $4.40( \pm 1.00)$ & $4.00( \pm 0.56)$ \\
Ethanol $(\% \mathrm{v} / \mathrm{v})$ & $11.03( \pm 2.25)$ & $7.53( \pm 1.16)$ \\
Total $\mathrm{SO}_{2}(\mathrm{mg} / \mathrm{L})$ & $29.95( \pm 2.11)$ & $19.62( \pm 1.77)$ \\
Free $\mathrm{SO}_{2}(\mathrm{mg} / \mathrm{L})$ & $7.68( \pm 0.57)$ & $5.99( \pm 0.29)$ \\
\hline
\end{tabular}

Due to its anti-oxidative and anti-microbial properties, sulfur dioxide plays an important role as preservative agent of fruits and wines (Alobo and Offonry, 2009). In present study, Total sulfur dioxide content ranged around $19.62 \pm 1.77 \mathrm{mg} / \mathrm{L}$ in Urwagwa from Rulindo and 29.95 $\pm 2.11 \mathrm{mg} / \mathrm{L}$ in Urwagwa wine from Ngoma. Note that there is no Rwandan legislation related to sulfur dioxide levels in banana wine. Otherwise, European Union Regulation (no $1493 / 1999$ y 1622/2000) states that sulfur dioxide should not exceed $160 \mathrm{mg} / \mathrm{L}$ as the maximum level for red wines and 210mg/l for white and rosé wines (EFSA, 2016). Based on this EU-regulation, all Urwagwa wine samples presented sulphite levels within the norms. However, compared to the Western wines from grape, sulfur dioxide content in Urwagwa wine is very lower due to the absence of sulphur additions during the Urwagwa winemaking. Sulfur dioxide found in banana wine derived from the yeast metabolism or as a component of finings or priming's (endogenous $\mathrm{SO}_{2}$ ). Yeast has the ability to produce sulfur dioxide, from the reduction of sulfate in water and grist material. $\mathrm{SO}_{2}$ levels will be increased if the sulfate supply to the yeast is increased, wort clarity is increased, wort oxygenation and pitching rate are lowered and fermentation temperature is reduced. Wine yeasts can produce up to $80 \mathrm{mg} / \mathrm{L}$ of sulfites depending on the fermentation conditions and their strains (Maik et al., 2009).

\subsection{Volatile compounds of Rwandan traditional banana wine "Urwagwa"}


Forty eight volatile compounds (Table 2), including 24 esters, 11 higher alcohols, 7 acids, 4 terpenes, 1 furan and 1 phenol were identified and quantified in SPEME extracts of Urwagwa wines made from the banana varieties "Gisukari and Kamaramasenge" collected from Rulindo and Ngoma districts, respectively. Only eight volatile compounds (6 esters and 2 high alcohols) were not common in all Urwagwa samples from Kamaramasenge and Gisukari banana varieties.

Esters constituted the main class of substances in terms of the number; they represented around $50 \%$ of the total volatile compounds identified in Urwagwa wine (Figure 2). Ethyl esters of fatty acids and acetates of higher alcohols were the dominating esters in the analyzed Urwagwa samples. Among them, ethyl acetate, ethyl caprate, ethyl caproate, ethyl nonanoate, ethy caprylate and isoamyl acetate represent the major esters in all analyzed Urwagwa wine samples. However, higher concentration of ethyl acetate $(51219 \mu \mathrm{g} / \mathrm{L})$ ethyl caprate $(49997 \mu \mathrm{g} / \mathrm{L})$ and ethyl caproate $(41010 \mu \mathrm{g} / \mathrm{L})$ and was found in Urwagwa from Rulindo district (Gisukari banana variety), while, isoamyl acetate (20344 $\mu \mathrm{g} / \mathrm{L})$, ethyl nonanoate $(18421 \mu \mathrm{g} / \mathrm{L})$ and ethyl caprylate $(16562 \mu \mathrm{g} / \mathrm{L})$ were in higher concentration in Urwagwa from Ngoma district (Kamaramasenge banana variety). Other important esters identified in all Urwagwa samples analyzed were 1-methylbutyl butanoate, ethyl butyrate, hexyl acetate, diethyl succinate, ethyl isovalerate and Phenetyl acetate. Isoamyl propionate, ethyl benzoate, ethyl 2-hexanoate, ethyl laurate and ethyl palmitate were detected only in Urwagwa samples from Rulindo. High amount of ethyl caproate, ethyl caprylate and ethyl caprate were also observed in wine prepared from Indian Cavendish banana (Ranjitha et al., 2013). These esters, formed primarily during the fermentation (Pretorius and Lambrechts, 2000; Suomalainen, 1981), are responsible of the fruity-flowery aromas in wine (Rocha et al., 2004; Verzera et al., 2008; Sánchez-Palomo et al., 2015). 
Table 2. Concentrations of volatile aroma components $(\mu \mathrm{g} / \mathrm{L})$ in Urwagwa wines from Rulindo (made from Gisukari banana variety) and Ngoma districts (made from Kamaramasenge banana variety)

\begin{tabular}{|c|c|c|c|c|}
\hline \multirow[t]{2}{*}{ Compounds } & \multirow[t]{2}{*}{ RI } & \multirow[t]{2}{*}{ aID } & \multicolumn{2}{|c|}{ Concentration $(\mu \mathrm{g} / \mathrm{L})$} \\
\hline & & & Ngoma & Rulindo \\
\hline \multicolumn{5}{|l|}{ Esters } \\
\hline Ethyl acetate & $613^{b}$ & MS/RIL & 29880 & 51219 \\
\hline Ethyl butyrate & $802^{b}$ & MS/RIL & 321 & 89 \\
\hline Ethyl isovalerate & 854 & MS & 215 & ND \\
\hline Isoamyl acetate & $879^{b}$ & MS/RIL & 20344 & 14789 \\
\hline Isobutyl butanoate & 898 & MS & 98 & 137 \\
\hline Isoamyl propionate & 913 & MS/RIL & ND & 563 \\
\hline Ethyl caproate & $999^{b}$ & MS/RIL & 32172 & 41010 \\
\hline 1-Hexyl acetate & 1012 & MS & 535 & 781 \\
\hline 1-methylbutyl butanoate & 1014 & MS/RIL & 567 & 145 \\
\hline Ethyl 2-hexanoate & 1038 & MS/RIL & ND & 144 \\
\hline 3-methyl butyl butanoate & 1045 & MS/RIL & 56 & 314 \\
\hline Ethyl benzoate & 1137 & MS/RIL & ND & 226 \\
\hline Ethyl succinate & 1182 & MS & 1056 & 588 \\
\hline Hexyl butanoate & 1190 & MS/RIL & 715 & ND \\
\hline Ethyl caprylate & $1198^{b}$ & MS/RIL & 16562 & 14120 \\
\hline Isopentyl hexanoate & 1203 & MS & 0.06 & 167 \\
\hline Phenetyl acetate & 1262 & MS & 286 & 364 \\
\hline Ethyl nonanoate & 1299 & MS/RIL & 18421 & 13116 \\
\hline Ethyl caprate & $1397^{b}$ & MS/RIL & 40516 & 49997 \\
\hline Ethyl undecanoate & 1480 & MS/RIL & 333 & ND \\
\hline Ethyl laurate & 1596 & MS/RIL & ND & 428 \\
\hline 3-methylbutyl decanoate & 1622 & MS & 77 & 152 \\
\hline Ethyl myristate & 1797 & MS/RIL & 0.7 & 0.05 \\
\hline Ethyl palmitate & 1991 & MS & ND & 93 \\
\hline
\end{tabular}

Table 2 continued

\begin{tabular}{lclll}
\hline Compounds & RI & ${ }^{\mathrm{a} I D}$ & \multicolumn{2}{c}{ Concentration $(\mu \mathrm{g} / \mathrm{L})$} \\
\cline { 5 - 5 } & & & Ngoma & Rulindo \\
\hline Alcohols & & & & \\
1-propanol & $<600^{\mathrm{b}}$ & MS & 76582 & 83331 \\
Isobutyl alcohol & $<600^{\mathrm{b}}$ & MS & 20567 & 29808 \\
2-pentanol & 698 & MS/RIL & ND & 1221 \\
Isoamyl alcohol & $741^{\mathrm{b}}$ & MS/RIL & 362356 & 388990 \\
2,3 butanediol & 790 & MS/RIL & 271 & 195
\end{tabular}




\begin{tabular}{|c|c|c|c|c|}
\hline 1-hexanol & $871^{\mathrm{b}}$ & MS/RIL & 1165 & 856 \\
\hline 1-heptanol & 935 & MS/RIL & 37 & 19 \\
\hline 1-octanol & 1082 & MS/RIL & 123 & 187 \\
\hline Phenethyl alcohol & $1119^{\mathrm{b}}$ & MS/RIL & 18034 & 21867 \\
\hline 1-nonanol & 1170 & MS/RIL & ND & 90 \\
\hline \multicolumn{5}{|l|}{ Acids } \\
\hline Acetic cid & $701^{b}$ & MS & 52451 & 112004 \\
\hline Isobutyric acid & 773 & MS & 10 & 19 \\
\hline Propanoic acid & 775 & MS & 914 & 610 \\
\hline Isovaleric acid & 889 & MS/RIL & 412 & 225 \\
\hline Caproic acid & $1066^{\mathrm{b}}$ & MS/RIL & 127 & 541 \\
\hline Caprylic acid & $1188^{\mathrm{b}}$ & MS/RIL & 378 & 720 \\
\hline Capric acid & $1380^{\mathrm{b}}$ & MS/RIL & 112 & 845 \\
\hline \multicolumn{5}{|l|}{ Terpenes } \\
\hline Limonene & 1019 & MS/RIL & 0.6 & 0.1 \\
\hline 1,8-cineole & 1037 & MS/RIL & 0.5 & 0.5 \\
\hline Dihydro-beta-Ionone & 1406 & MS/RIL & 0.6 & 0.2 \\
\hline Trans-beta-Farnesene & 1421 & MS/RIL & 0.1 & 0.3 \\
\hline \multicolumn{5}{|l|}{ Others } \\
\hline 2-pentyl furan & 989 & MS/RIL & 17 & 75 \\
\hline 2-methoxy 4-vinyl phenol & 1315 & MS/RIL & 878 & 112 \\
\hline
\end{tabular}

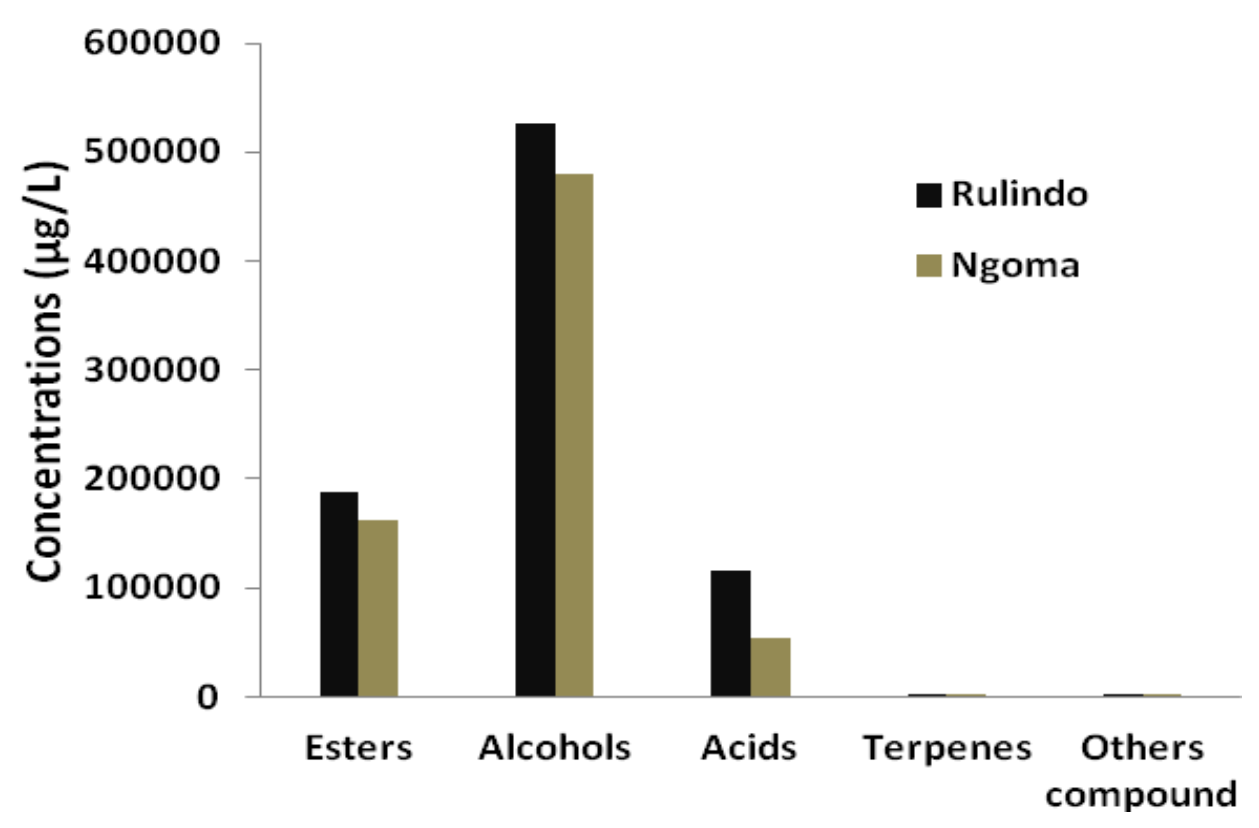


Figure 2. Concentration of different groups of volatile compounds in Urwagwa wines made from Kamaramasenge (Ngoma) and Gisukari (Rulindo) banana varieties.

Alcohols are quantitatively the largest group of the volatile compounds in Urwagawa wine of Rwanda (Figure 2). This group is composed of 1- propanol, 2-methyl-1-propanol, 2-methyl1-butanol, 2,3 butanediol, 1-hexanol, 1-heptanol, 1-octanol, 1-nonanol, and phenyl alcohol. 2-pentanol and 1-nonanol were found solely in Urwagwa samples from Rulindo district. However, 1-propanol, 2-methyl-1-propanol, 3-methyl-1-butanol and phenyl alcohol are major higher alcohol found in all Urwagwa samples from Rwanda. These fermentation-derived products contribute to the alcoholic, floral and green grass aroma of the wine (SanchezPalomo et al., 2015); they are also known to be important as precursors of corresponding esters which contribute most significantly to the wine aroma.

Fatty acids constituted also the abundant group in the aromatic components of wines. In the present study, acetic acid was the major fatty acid found in all Urwagwa wine samples analyzed. However, the highest concentration was observed in Urwagwa made from Gisukari banana variety. At low level, acetic acid contributes to the complexity of the wine bouquet, but, they can have negative effect on wine aroma when above their thresholds (Swiegers and Pretorius, 2005). Caprylic, caproic, capric, propanoic, isobutyric and isovaleric acids were also detected in all analyzed Urwagwa wine samples. These fatty acids are generally produced by yeast metabolism during fermentation and accumulate in wine (Swiegers and Pretorius, 2005). The amount of medium-chain fatty acids (caprylic and capric acid) released into the fermentation medium depending to the yeast strain, medium composition and fermentation conditions (Krauss and Forch, 1975; Jones et al., 1981). Although they are do not associated with wine quality, these fatty acids have a characteristic odor and are interesting as flavor factors in wine. However, caprilyc, caproic and capric acids can affect the wine aroma negatively when their sum is at the level beyond $20 \mathrm{mg} / \mathrm{L}$ (Shinohara, 1985). 
Four terpenes were identified in Urwagwa wine made from Kamaramasenge and Gisukari banana varieties, including limonene, 1-8 cineole, trans-beta-Farnesene and dihydro-betaionone. The terpenes can originate from the raw material (Peña-Alvarez et al., 2004) or liberated by alpha-glycosidases from yeasts during the fermentation process (King and Dickinson, 2000). Despite their generally low concentrations, the terpenes are regarded to be a positive quality factor of a wine because terpenes contribute to its aroma, serving as indicators to differentiate the wine, and may contribute to floral note of the wine (Falqué al., 2001; Calleja and Falqué, 2005). In the present work, the terpenes content does not allow distinguish the Urwagwa wine made from Kamaramasenge banana (Ngoma district) variety to those from Gisukari banana variety (Rulindo district). However, Limonene and 1,8-cineole were also found in Western wine where it serves as indicator to distinguish the varieties and quality of grape (Zhang et al., 2007). Capone et al. (2012) reported that the presence of Eucalyptus leaves and to a lesser extent grape vine leaves and stems is the major contributor to the 1,8-cineole (Eucalyptol) concentration in grape wine. The presence of 1,8-cineole in Urwagwa wine can also be due to the presence of Eucalyptus leaves during the traditional process of green bananas ripening and juice extraction.

Other compounds detected in Urwagwa wine made from Kamarasenge and Gisukari banana varieties were 2-penthylfuran and 2-methoxy 4-vinyl phenol. 2-pentylfuran has always been associated to the Maillard reaction as it is one of the main pathways generating furan. The presence of 2-Pentylfuran was also reported in Brazilian merlot wine (Welke et al., 2012) and sorghum beer (Lyumugabe et al., 2013). 2-methoxy 4-vinyl phenol is a major odour compound in many white wines, and aroma of the pure compound is described as wine-like aroma (Comuzzo et $a l, 2006)$. Ranjitha et al. (2013) reported that origin of this compound in banana wine lies in the fermentation process because it was absent in banana juice. 


\subsection{Odour activity values (OAVs) and Sensory characteristics of Urwagwa}

The characterization of potentially most important volatile aroma compound of Urwagwa wine was determined by odour activity values (OAVs), i.e. the ratio of the concentration of the compound to the odour threshold in wine (Sanchez-palmos et al., 2015). Table 3 lists the odour activity values for 15 volatile aroma compounds with OAV > 1 in Urwagwa wine. Compounds that exhibited OAVs higher than 1 were considered to contribute individualely to the Urwagwa aroma and were designated would be the characteristic aroma compounds for Urwagwa. The results showed that ethyl caprylate, ethyl caproate, ethyl caprate, ethyl acetate, isoamyl acetate, ethyl acetate, ethyl butyrate, phenetyl acetate, 3-methyl-1-butanol, phenety alcohol, caprylic acid, 1-octanol and isovaleric acid exhibited odour activity values higher than 1 for all Urwagwa wines studied. These compounds can contribute directly to the aroma profile of Urwagwa wine. However, as odour threshold is affected by additive, synergic and antagonistic effects of the volatile compounds in a matrix, the identification of the most powerful odorants only on the basic of their OAVs should be considered provisional (Sanchez-palomo et al., 2015). At present, this property can only be verified by means of

Table 3. OAVs of the aroma compounds of Urwagwa from Ngoma and Rulindo districts

\begin{tabular}{|l|c|l|l|l|}
\hline \multicolumn{1}{|c|}{ Compounds } & $\begin{array}{l}\text { Odour } \\
\text { threshold } \\
(\mu \mathrm{g} / \mathrm{L})\end{array}$ & \multicolumn{1}{|c|}{ Odor description } & Ngoma & \multicolumn{1}{|c|}{ Rulindo } \\
\hline Ethyl acetate & $7500^{\mathrm{a}}$ & Fruity, sweet & 4.0 & 6.8 \\
\hline Ethyl butyrate & $20^{\mathrm{b}}$ & Fruity & 16.1 & 4.5 \\
\hline Ethyl caproate & $5^{\mathrm{a}}$ & Fruity, anise & 6434 & 8202 \\
\hline Ethyl caprylate & $2^{\mathrm{a}}$ & Fruity,, floral & 8182 & 7060 \\
\hline Ethyl caprate & $200^{\mathrm{a}}$ & Fruity, fatty, pleasant & 206.6 & 259.0 \\
\hline Isoamyl acetate & $30^{\mathrm{a}}$ & Banana & 678.1 & 493.1 \\
\hline Phenetyl acetate & $250^{\mathrm{a}}$ & Floral, pleasant, & 1.2 & 1.5 \\
\hline Isoamyl alcohol & $30000^{\mathrm{a}}$ & Cheese & 12.1 & 10.3 \\
\hline 1-octanol & $120^{\mathrm{a}}$ & Intense citrus, roses & 1.0 & 1.5 \\
\hline Phenethyl alcohol & $14000^{\mathrm{a}}$ & Rose, pollen, perfume & 1.9 & 1.7 \\
\hline
\end{tabular}




\begin{tabular}{|l|c|l|l|l|}
\hline Isovaleric acid & $33^{\mathrm{c}}$ & Fatty, rancid & 12.5 & 3.8 \\
\hline Caprylic acid & $500^{\mathrm{a}}$ & cheese, fatty acid, rancid & $<1$ & 1.4 \\
\hline
\end{tabular}

${ }^{a}$ Guth (1997). ${ }^{b}$ Dragone et al. (2009). ${ }^{c}$ Ferreira et al. (2000).

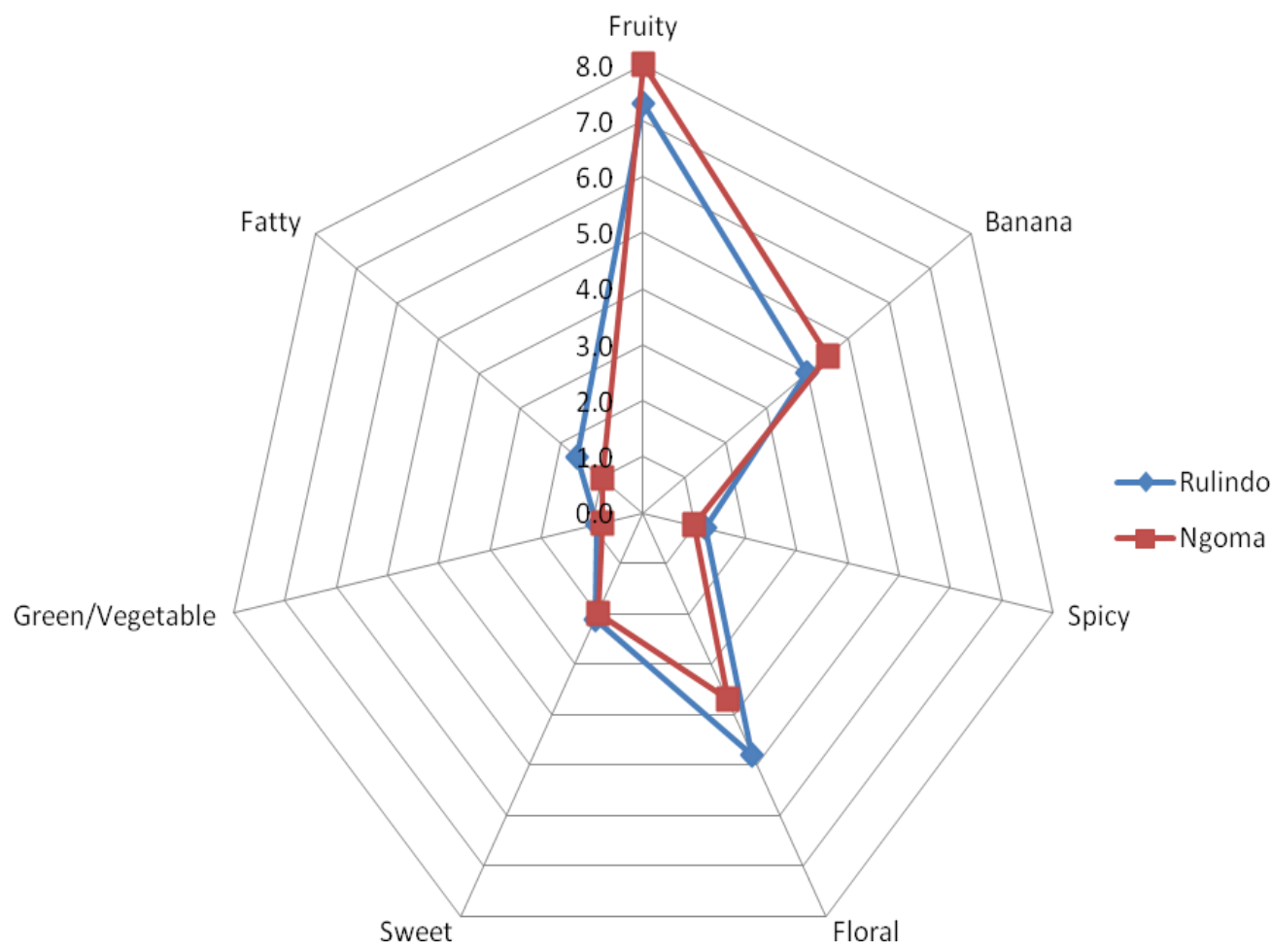

Figure 3. Descriptive sensory analysis of the analyzed Urwagwa wine samples

sensory tests, although an approximation can be obtained by considering the variability in geometric terms of concentration or of concentrations normalised by their thresholds (López et al., 2003).

To define the overall aroma profile of Urwagwa wine, the descriptive sensory analysis was performed by a selected panel of ten assessors trained over five sessions. The aroma descriptors used during sensory analysis were defined in preliminary session and represent the main constituents of the aroma profile of the wine: fruity, floral, banana, green/fresh, sweet, spice and fatty. The results of sensory analysis (Figure 3) showed that all Urwagwa wines have the similar aroma profile. The highest score obtained was those of fruity note (7.3 
for Urwagwa wines from Rulindo, and 8.0 for those from Ngoma), followed by floral note (3.7 for Urwagwa wines from Ngoma, and 4.8 for those from Rulindo) and banana note (4.0 Urwagwa wines from Rulindo, and 4.5 for those from Ngoma). These results show that the overall aroma profile of all Urwagwa wines studied is dominated by fruity note. Based on the OAVs, the fruity character of Urwagwa wines can due be to the high amount of ethyl and acetate esters, namely, ethyl caprylate, ethyl caprate, ethyl caproate, ethyl butyrate and ethyl acetate; while floral and banana notes can be correlated to the isoamyl acetate, phenethyl acetate, ethyl caprylate, phenethyl alcohol and 1-octanol. However, other compounds identified in Urwagwa wine (OAV less than 1) may also have contributed to enhance the intensity of some notes already present because of the synergistic effects with other odorous compounds in matrix of the wine.

\section{CONCLUSION}

The aroma profiles of Urwagwa wine samples collected from the districts of Rulindo (made from Gisukari banana variety) and Ngoma (made from Kamaramasenge banana variety) were investigated. The results showed that the aroma profiles of these two types of Urwagwa wine were not significantly different. Forty eight volatile aroma compounds, including esters, higher alcohols, acids, terpenes, furan and phenol were identified and quantified in Urwagwa wine. Among them, ethyl caprylate, ethyl caproate, ethyl caprate, ethyl acetate, isoamyl acetate, ethyl acetate, ethyl butyrate, phenethyl acetate, phenethyl alcohol, caprylic acid, 1octanol and isovaleric acid exhibited OAVs $>1$, and are considered as the major contributors of aromatic character of Urwagwa wine; described as fruity, floral banana, sweet and fatty notes. However, the overall aroma profile of all Urwagwa wines studied was dominated by the fruity note due to the high amount of ethyl caprylate, ethyl caprate and ethyl caproate in this Rwandan traditional banana wine. 


\section{Acknowledgements}

This work was funded by a grant from the University of Rwanda, under financial support from Swedish International Development Agency (SIDA). 


\section{References}

Alobo, A.P. and Offonry, S. (2009) Characteristics of coloured wine produced from roselle (Hibiscus sabdariffa) calyx extract. Journal of the Institute of Brewing,115, pp. 91-94.

Calleja, A., and Falqué, E. (2005) Volatile composition of Mencía wines. Food Chemistry, 90, pp. 357- 363.

Capone, D.L., Jeffery, D.W., and Sefton, M.A. (2012) Vineyard and fermentation studies to elucidate the origin of 1,8-cineole in Australian red wine. J Agric. Food Chem., 60, pp. 22812287.

Comuzzo, P., Tat, L., Tonizzo, A. and Battistutta, F. 2006 Yeast derivatives (extracts and autolysates) in winemaking: Release of volatile compounds and effects on wine aroma volatility. Food Chem., 99, pp. 217-230.

Dragone, G., Oliveira, J.M., Teixeira JA. (2009) Characterisation of volatile compounds in alcoholic beverage produced by whey fermentation. Food Chemestry, 112, pp. 929-935.

EFSA. (2016) Scientific Opinion on the re-evaluation of sulfur dioxide (E 220), sodium sulfite (E221), sodium bisulfite (E222), sodium metabisulfite (E223), potassium metabisulfite (E224 ), calcium sulfite (E226), calcium bisulfite (E 227) and potass. EFSA Journal, 14, pp.1-151.

Falqué, E., Fernández, E., and Dubourdieu, D. (2001) Differentiation of white wines by their aromatic index. Talanta, 54, pp. 271-281.

Ferreira, V., Lápez, R., and Cacho, J.F. (2000) Quantitative determination of the odorants of young red wines from different grape varieties. J. Sci. Food Agric., 80, pp.1659-1667.

Guth, H. (1997) Identification of character impact odorants of different white wine varieties. Journal of Agricultural and Food Chemistry, 45, pp. 3022-3026.

Hellín, P., Manso, A., Flores, P., and Fenoll, J. (2010) Evolution of aroma and phenolic compounds during ripening of 'superior seedless' grapes. Journal of Agricultural and Food Chemistry, 58, pp. 6334-6340.

ISO (International Organization for Standardization) 3591:1977. Sensory analysis -Apparatus -- Wine-tasting glass. Available online at https://www.iso.org/standard/9002.html

ISO (International Organization for Standardization) 18589:1988. Sensory analysis -- General guidance for the design of test rooms. Available online at https://www.iso.org/standard/15879.html

ISO (International Organization for Standardization) 4121: 2003. Sensory analysis -Guidelines for the use of quantitative response scales. Available online at https://www.iso.org/standard/33817.html

ISO (International Organization for Standardization) 4121: 2003. Sensory analysis -Methodology -- General guidance for establishing a sensory profile. Available online at https://www.iso.org/standard/37227.html 
Jones, R. P., Pamment, N., and Greenfield, P. F. (1981) Alcohol fermentation by yeasts - the effect of environmental and other characteristics. Process Biochemistry, 16, pp. 42-49.

King, A., and Dickinson, J. R. (2000) Biotransformation of monoterpene alcohols by Saccharomyces cerevisiae, Torulaspora delbrueckii and Kluyveromyces lactis. Yeast, 16, pp. 499-506.

Krauss, G., and Forch, M. (1975) The influence of different fermentation methods on the formation of lower free fatty acids. Proc Am Soc Brew Chem., 33, pp. 37-41.

Lawless, H. (1995) Dimensions of sensory quality: a critique. Food Quality Prefer,6, pp.191199.

Li, H., Tao, Y. S., Kang, W. H., and Yin, C. L. (2006) Wine aroma analytical investigation progress on GC [review]. Food Science and Biotechnology, 25, pp.99-104.

Li, H., Tao, Y. S., Wang, H., and Zhang, L. (2008) Impact odorants of Chardonnay dry white wine from Changli County (China). European Food Research and Technology, 227, pp. 287292.

López, R., Ortin, N., Perez-Trujillo, J.P., Cacho, J., and Ferreira, V. (2003) Impact odorants of different white wines from the Canary Islands. J. Agric.Food Chem., 51, pp. 3419-3425.

Lyumugabe, F., Bajyana, E., Wathelet J.P., and Thonart, Ph. (2013) Volatile compounds of the traditional sorghum beers ikigag brewed with Vernonia amygdalina "umubirizi". Cerevisia, 37, pp. 89-96.

Maik, W., Doris, R., and Philippe, C. (2009) Yeasts and natural production of sulphites. J enology and viticulture, 12, pp.1-5.

Mukantwali, C., Shingiro, J.B., and Dusengemungu, L. (2008) Banana production, post harvest and marketing in Rwanda. Technical Report, Kigali Institute of Science and Technology, Rwanda.

Muñoz, M. (2002) Sensory evaluation in quality control: an overview, new developments and future opportunities. Food Quality Prefer, 13, pp. 329-339.

Munyangendo, E. (1983) Etude variétale de la valeur vinicole des bananes cultivées au Rwanda: isolement et étude de souches de levures de vins de bananes de fabrication traditionnelle de différentes régions du Rwanda. Ph.D Thesis, University of Nancy, France

Nsabimana, A., and Vas Staden, J. (2007) Assessment of genetic diversity of highland bananas from the National Banana Germplasma collection at Rubona, Rwanda using RAPD markers. Sci. Hortic., 113, pp. 293-299.

Peña-Alvarez, A., Diáz, L., Medina, A., Labastida, C., Capella, S., and Vera, L. E. (2004) Characterization of three Agave species by gas chromatography and solidphase-gas chromatography-mass spectrometry. Journal of Chromatography A, 1027, pp. 131-136.

Perestrelo, R., Fernandes, A., Albuquerque, F. F., Marques, J. C., and Câmara, J. S. (2006) Analytical characterization of the aroma of Tinta Negra Mole red wine: Identification of the main odorants compounds. Analytica Chimica Acta, 563, pp. 154-164. 
Pino, J.A., Marquez, E., Quijano, C. E., and Castro, D. (2010) Volatile compounds in noni (Morinda citrifolia L.) at two ripening stages. Ciênc. Tecnol. Aliment., Campinas, 3, pp. 183187.

Pretorius, I. and Lambrechts, M. (2000) Yeast and its importance to wine aroma: a review. South African Journal of Enology and Viticulture, 21, pp 97 -129.

Ranjitha, K., Narayana, C.K., and Roy,T.K. (2013) Aroma profile of fruit juice and wine prepared from Cavendish banana (Musa sp., Group AAA) cv. Robusta. J Hortl. Sci., 8, pp. 217-223.

Richard, A. S., and Ann, C. N., (1988) Comparison of the Effects of Concentration, pH and Anion Species on Astringency and Sourness of Organic Acids. Chem. Senses, 23, pp.343349.

Rocha, S. M., Rodrigues, F., Coutinho, P., Delgadillo, I., and Coimbra, M.A. (2004) Volatile composition of Baga red wine: assessment of the identification of the would-be impact odorants. Analytica Chimica Acta, 513, pp. 257-262.

Sánchez-Palomo, E., Gómez García-Carpintero, E., and González Viñas, M.A., (2015). Aroma Fingerprint Characterisation of La Mancha Red Wines. South African J. Enol. Vitic., 36, pp. 117-125.

Shale, K., Mukamugema, J., Lues, R.J., and Venter, P., De Smidt, O. (2012) Microbiota associated with commercially produced traditional banana beer in Rwanda. Scientific Research and Essays, 7, pp. 4037-4046.

Shale, K., Mukamugema, J. Lues, R.J., and Venter, P. (2014) Possible microbial and biochemical contaminants of an indigenous banana beer 'Urwagwa': A mini review, African J. Food Science, 8, pp. 376-389.

Shinohara, T. (1985) Gas chromatographic analysis of volatile fatty acids in wines. Agricultural and Biological Chemistry, 49, pp. 2211-2212.

Suomalainen, H., 1981. Yeast esterases and aroma esters in alcoholic beverages. J. Inst. Brew., 87, 296-300.

Swiegers, J. H., and Pretorius, I. S. (2005). Yeast modulation of wine flavor. Advances in Applied Microbiology, 57, pp. 131-175.

Varela, P., and Gàmbara, P. (2006) Sensory descriptive analysis of Uruguayan Tannat wine: correlation to quality assessment. J. Sensory Studies, 21, pp. 203-217.

Verzera, A., Ziino, M., Scacco, A., Lanza, C.M., Mazzaglia, A., Romeo, V., and Condurso, C. (2008) Volatile compound and sensory analysis for the characterization of an Italian white from "Inzolia" grapes. Food Anal Methods, 1, pp.144-151.

Vilanova, M. (2006) Sensory descriptive analysis and consumer acceptability of Godello wines from Valdeorras Appellation Origen Controlée (NorthWest Spain). J Sensory Studies, 21, pp. 362-372.

Welke, J.E., Manfroi, V., Zanus, M., Lazarotto, M., and Alcaraz Zin, C.( 2012) Characterization of the volatile profile of Brazilian Merlot wines through comprehensive two 
dimensional gas chromatography time-of-flight mass spectrometric detection., Journal of Chromatography A,1226, pp. 124-139.

Zhang, M., Xu, Q., Duan, C., Qu, W., \& Wu, Y. (2007) Comparative study of aromatic compounds in young red wines from cabernet sauvignon, cabernet franc, and cabernet gernischet varieties in China. Journal of Food Science, 72, pp. 248-252. 